\title{
Effects of Viscous Dissipation on the Thermal Boundary Layer of Pseudoplastic Power-Law Non-Newtonian Fluids Using Discretization Method and the Boubaker Polynomials Expansion Scheme
}

\author{
Karem Boubaker, ${ }^{1}$ Botong Li, ${ }^{2}$ Liancun Zheng, ${ }^{2}$ Ali H. Bhrawy, ${ }^{3}$ and Xinxin Zhang ${ }^{4}$ \\ ${ }^{1}$ ESSTT, Université de Tunis, 63 Rue Sidi Jabeur, 5100 Mahdia, Tunisia \\ ${ }^{2}$ Department of Mathematics and Mechanics, University of Science and Technology Beijing, Beijing 100083, China \\ ${ }^{3}$ Department of Mathematics, Faculty of Science, King Abdulaziz University, Jeddah 21589, Saudi Arabia \\ ${ }^{4}$ School of Mechanical Engineering, University of Science and Technology Beijing, Beijing 100083, China
}

Correspondence should be addressed to Karem Boubaker, mmbb11112000@yahoo.fr

Received 6 January 2012; Accepted 31 January 2012

Academic Editors: S. Hashimoto and G. Polidori

Copyright (C) 2012 Karem Boubaker et al. This is an open access article distributed under the Creative Commons Attribution License, which permits unrestricted use, distribution, and reproduction in any medium, provided the original work is properly cited.

Heat transfer of pseudoplastic power-law non-Newtonian fluids aligned with a semi-infinite plate is studied. Unlike in most classical works, the effects of viscous dissipation which is coupled with the temperature-dependent thermal diffusivity are considered in the energy equation. The discretization method is used to convert the governing partial differential equations into a set of nonlinear ordinary differential equations. The solutions are presented numerically by using the shooting technique coupled with the Newtonian method and the Boubaker polynomials expansion scheme. The effects of power-law index and the Zheng number on the dynamics are analyzed. The associated heat-transfer characteristics are also tabulated in some domains of the said parameters.

\section{Introduction}

Since 1960, a considerable attention has been devoted to predict the drag force behavior and energy transport characteristics of the non-Newtonian fluid flows. The main reason for this is probably that fluids (such as molten plastics, pulps, slurries, emulsions), which do not obey the assumption of Newtonian fluids that the tress tensor is directly proportional to the deformation tensor, are found in various engineering applications. A variety of constitutive equations have been proposed to describe the flow and heat transfer non-Newtonian characteristics, among them the empirical Ostwaald-de Waele model, which is known as the so-called power-law model, gained much acceptance. For an incompressible power law non-Newtonian fluid, its shear stress is characterized as $\tau_{x y}=K|\partial U / \partial Y|^{n-1} \partial U / \partial Y$ and the kinematics' viscosity is $\nu=\gamma|\partial U / \partial Y|^{n-1}$ (where $\gamma=K / \rho, \rho$ is the density and $K$ is the consistency index). The case $n=1$ corresponds to a Newtonian fluid. $0<n<1$ is descriptive of pseudoplastic fluids while $n>1$ describes dilatant's fluids.

Schowalter [1] and Acrivos et al. [2] successfully applied the power-law model to the boundary layer problems. The boundary-layer equations were formulated, and the conditions for the existence of similarity solutions were established. Following the pioneering works of Schowalter and Acrivos et al. [1, 2], Wang [3, 4], and Hady [5] analyzed the mixed convection heat transfer from a vertical or horizontal plate of non-Newtonian fluids with uniform surface heat flux. Kumari et al. [6] considered the freeconvection boundary-layer flow of a non-Newtonian fluid along a vertical wavy surface. Howell et al. [7] and Rao et al. [8] examined the momentum and heat transfer of the power-law fluids on a continuous moving surface. Hassanien et al. [9] investigated the heat transfer in power-law flow 
over a nonisothermal stretching sheet. Luna et al. [10] considered the case of conjugated heat transfer of a power law laminar fluid in circular ducts. Pinarbasi and Imal [11] extended their work to the viscous heat effects on the linear stability of Poiseuille flow of an inelastic fluid. Chen [12] analyzed the effect of viscous dissipation on heat transfer in non-Newtonian power law liquids over an unsteady stretching sheet. For the non-Newtonian powerlaw fluids, the hydrodynamic problem of the MHD boundary layer flow over a continuously moving surface has been dealt with by several authors (e.g., Andersson et al. [13], Cortell [14], and M. A. A. Mahmoud and M. A. E. Mahmoud [15]). The effect of magnetic field is found to decrease the velocity distribution and thus to increase the skin-friction coefficient.

It seems that, in all the works cited above, the power law kinematic viscosity was applied only on the momentum equations and the thermal conductivity is still treated as constant. This is inconsistent with the known fact that the change of viscosity should affect both the momentum and heat equation of the power law flows. Pop et al. [16, 17] proposed a model which states that the thermal conductivity of non-Newtonian fluids was power-law-dependent on the velocity gradient. Based on this consumption, Gorla et al. and Ece and Buyuk [18, 19] performed a boundary-layer analysis for the free convection flow over a vertical flat plate embedded in a porous medium saturated by a power-law non-Newtonian fluid and gave the similarity solution to the classical boundary layer equations of the power-law wall plume problem.

Motivated by works mentioned above, this paper takes the effects of power law kinematic viscosity into account in the boundary layer heat transfer equations. In terms of the analogy between viscosity diffusion and thermal diffusion, we assumed that the thermal conductivity will be chosen as $k(T)=\lambda|\partial T / \partial Y|^{n-1}$ and the thermal diffusivity $\alpha$ be defined as $\alpha=\omega|\partial T / \partial Y|^{n-1}$ with $\omega=\lambda / \rho c_{P}$ as a positive constant ( $c_{P}$ is the specific heat at constant pressure) $[20,21]$. We first formulate a thermal boundary layer equation for the power-law non-Newtonian fluids with a new variable thermal conductivity and provide similarity solutions.

\section{Formalization of the Nonlinear Boundary Value Problem}

Consider a semi-infinite plate at uniform wall temperature aligned with a power law fluid of constant speed $U_{\infty}$. In the presence of viscous dissipation, the laminar boundary layer equations are written as:

$$
\begin{gathered}
\frac{\partial U}{\partial X}+\frac{\partial V}{\partial Y}=0 \\
U \frac{\partial U}{\partial X}+V \frac{\partial U}{\partial Y}=\frac{1}{\rho} \frac{\partial \tau_{x y}}{\partial Y}, \\
U \frac{\partial T}{\partial X}+V \frac{\partial T}{\partial Y}=\frac{\partial}{\partial Y}\left(\alpha \frac{\partial T}{\partial Y}\right)+\frac{\nu}{c_{p}}\left(\frac{\partial U}{\partial Y}\right)^{2},
\end{gathered}
$$

where Uand Vare the velocity components along $X$ and $Y$ directions, respectively. The boundary conditions are

$$
\begin{gathered}
\left.U\right|_{Y=0}=0,\left.\quad V\right|_{Y=0}=0,\left.\quad U\right|_{Y=+\infty}=U_{\infty}, \\
\left.T\right|_{Y=0}=T_{w},\left.\quad T\right|_{Y=+\infty}=T_{\infty} .
\end{gathered}
$$

The following dimensionless variables are introduced:

$$
\begin{gathered}
x=\frac{X}{L}, \quad y=\left[\frac{\rho U_{\infty}^{2-n} L^{n}}{K}\right]^{1 / n+1} \frac{Y}{L}, \\
u=\frac{U}{U_{\infty}}, \quad v=\left[\frac{\rho U_{\infty}^{2-n} L^{n}}{K}\right]^{1 / n+1} \frac{V}{U_{\infty}}, \\
\theta=\frac{T-T_{w}}{T_{\infty}-T_{w}}, \\
N_{\mathrm{Zh}}=\frac{U_{\infty}^{n-1} \gamma}{\left|T_{\infty}-T_{w}\right|^{n-1} \omega}, \quad Z^{*}=\frac{U_{\infty}^{2}}{c_{p}\left(T_{\infty}-T_{w}\right)},
\end{gathered}
$$

$N_{Z h}$ is defined as the Zheng number.

The boundary layer equations then become

$$
\begin{gathered}
\frac{\partial u}{\partial x}+\frac{\partial v}{\partial y}=0 \\
u \frac{\partial u}{\partial x}+v \frac{\partial v}{\partial y}=\frac{\partial}{\partial y}\left(\left|\frac{\partial u}{\partial y}\right|^{n-1} \frac{\partial u}{\partial y}\right), \\
u \frac{\partial \theta}{\partial x}+v \frac{\partial \theta}{\partial y}=\frac{1}{N_{Z h}} \frac{\partial}{\partial y}\left(\left|\frac{\partial \theta}{\partial y}\right|^{n-1} \frac{\partial \theta}{\partial y}\right)+Z^{*}\left|\frac{\partial u}{\partial y}\right|^{n-1}\left(\frac{\partial u}{\partial y}\right)^{2},
\end{gathered}
$$

with the boundary conditions:

$$
\begin{gathered}
\left.u\right|_{y=0}=0,\left.\quad v\right|_{y=0}=0,\left.\quad u\right|_{y=+\infty}=1, \\
\left.\theta\right|_{y=0}=0,\left.\quad \theta\right|_{y=+\infty}=1 .
\end{gathered}
$$

Equations (8)-(11) are super-nonlinear. Since the problem is very complex to solve analytically, a discretized model may be a considerable approach.

The stream function $\psi(x, y)$, similarity variable $\eta$, and dimensionless temperature function $w(\eta)$ are defined as:

$$
\begin{gathered}
\psi=A x^{\tilde{\alpha}} f(\eta), \quad \theta(x, y)=w(\eta), \\
\eta=B x^{\tilde{\beta}} y,
\end{gathered}
$$

where $A, B, \tilde{\alpha}$, and $\tilde{\beta}$ are constant to be determined, and $f(\eta)$ denotes the dimensionless stream function. The $u$ and $v$ velocity component are

$$
\begin{gathered}
u=\frac{\partial \psi}{\partial y}=A B x^{\tilde{\alpha}+\widetilde{\beta}} f^{\prime}(\eta), \\
v=\frac{\partial \psi}{\partial x}=-A \tilde{\alpha} x^{\tilde{\alpha}-1}\left[f(\eta)-\eta f^{\prime}(\eta)\right] .
\end{gathered}
$$


Substituting $u$ and $v$ into (8)-(11) combining with

$$
\begin{gathered}
\tilde{\beta}=-\tilde{\alpha}, \quad A B=1, \\
\tilde{\alpha}=\frac{1}{n+1}, \quad B=(n+1)^{(-1 /(n+1))},
\end{gathered}
$$

we arrive at the nonlinear boundary value problems of the form as:

$$
\begin{gathered}
\left(\left|f^{\prime \prime}(\eta)\right|^{n-1} f^{\prime \prime}(\eta)\right)^{\prime}+f(\eta) f^{\prime \prime}(\eta)=0, \\
f(0)=0, \quad f^{\prime}(0)=0,\left.\quad f^{\prime}(\eta)\right|_{\eta=+\infty}=1, \\
f(\eta) w^{\prime}(\eta)+\frac{1}{N_{Z h}}\left(\left|w^{\prime}(\eta)\right|^{n-1} w^{\prime}(\eta)\right)^{\prime}, \\
+Z^{*}\left|f^{\prime \prime}(\eta)\right|^{n-1}\left(f^{\prime \prime}(\eta)\right)^{2}=0, \\
w(0)=0,\left.\quad w(\eta)\right|_{\eta=+\infty}=1 .
\end{gathered}
$$

\section{Discretization Method Solution}

In order to obtain numerical solutions, we transfer the problem (15)-(18) to a system of four first-order equations by denoting the $f, f^{\prime}, f^{\prime \prime}, w, w^{\prime}$ using variables $f, u, v, w, y$, respectively:

$$
\begin{gathered}
f^{\prime}=u, \\
u^{\prime}=v, \\
v^{\prime}=-\frac{1}{n} f v^{2-n}, \\
w^{\prime}=y, \\
y^{\prime}=-\frac{Z^{*} \cdot N_{Z h}}{n} y^{1-n} v^{n+1}-\frac{N_{Z h}}{n} f y^{2-n} .
\end{gathered}
$$

The corresponding boundary conditions are

$$
\begin{gathered}
f(0)=0, \quad u(0)=0, \quad w(0)=0 \\
u(+\infty)=1, \quad w(+\infty)=1 .
\end{gathered}
$$

We introduce the parameters tand $s$ as

$$
v(0)=t, \quad y(0)=s .
$$

Then, the problem is to find parameters $t$ and $s$ such that the solution to (19)-(24), (26) satisfies the boundary conditions (25).

The solution to the initial-value problems (19)-(24), (26) can be denoted as $f(\eta, t, s), u(\eta, t, s), v(\eta, t, s), w(\eta, t, s)$, and $y(\eta, t, s)$. Thus the following equations are to be solved:

$$
\begin{aligned}
& \phi(t, s)=u(+\infty, t, s)-1=0, \\
& \varphi(t, s)=w(+\infty, t, s)-1=0 .
\end{aligned}
$$

The Newtonian method and Runge-Kutta scheme are convenient to solve the nonlinear problem above.

\section{BPES Solution}

The Boubaker polynomials expansion scheme (BPES) [2237] solutions starts from assigning the following expression:

$$
\begin{gathered}
w(\eta)=\frac{1}{2 M} \sum_{j=1}^{M} \xi_{j} \times B_{4 j}\left(\omega_{j} \varepsilon(\eta)\right), \\
\varepsilon(\eta)=(\eta+1) e^{-\eta},
\end{gathered}
$$

with $B_{4 j}: 4 j$-order Boubaker polynomials, $\omega_{j}: B_{4 j}$ minimal positive roots, $M$ : a prefixed integer, $\omega_{j}: B_{4 j}$ minimal positive roots, and $\left.\xi_{j}\right|_{j=1 \ldots . M}$ : unknown pondering real coefficients.

Using expression (29), the boundary conditions:

$$
\begin{aligned}
& \left.w(\eta)\right|_{\eta=0}=0, \\
& \lim _{\eta \rightarrow+\infty} w(\eta)=1
\end{aligned}
$$

are verified automatically with reference to the Boubaker polynomials properties:

$$
\begin{gathered}
\left.\sum_{q=1}^{N} B_{4 q}(x)\right|_{x=0}=-2 N \neq 0, \\
\left.\sum_{q=1}^{N} B_{4 q}(x)\right|_{x=\alpha_{q}}=0, \\
\left.\sum_{q=1}^{N} \frac{d B_{4 q}(x)}{d x}\right|_{x=0}=0, \\
\left.\sum_{q=1}^{N} \frac{d B_{4 q}(x)}{d x}\right|_{x=\alpha_{q}}=\sum_{q=1}^{N} H_{q}, \\
\left.\frac{d^{2} B_{4 q}(x)}{d x^{2}}\right|_{x=0}=\frac{8}{3}\left(N\left(N^{2}-1\right)\right), \\
\left.\sum_{q=1}^{N} \frac{d^{2} B_{4 q}(x)}{d x^{2}}\right|_{x=\alpha_{q}}=\sum_{q=1}^{N} G_{q},
\end{gathered}
$$

with

$$
H_{n}=B_{4 n}^{\prime}\left(\alpha_{n}\right)=\left(\frac{4 \alpha_{n}\left[2-\alpha_{n}^{2}\right] \times \sum_{q=1}^{n} B_{4 q}^{2}\left(\alpha_{n}\right)}{B_{4(n+1)}\left(\alpha_{n}\right)}+4 \alpha_{n}^{3}\right),
$$

$$
\begin{aligned}
G_{q} & =\left.\frac{d^{2} B_{4 q}(x)}{d x^{2}}\right|_{x=\alpha_{q}} \\
& =\frac{3 \alpha_{q}\left(4 q \alpha_{q}^{2}+12 q-2\right) H_{q}-8 q\left(24 q^{2} \alpha_{q}^{2}+8 q^{2}-3 q+4\right)}{\left(\alpha_{q}^{2}-1\right)\left(12 q \alpha_{q}^{2}+4 q-2\right)} .
\end{aligned}
$$




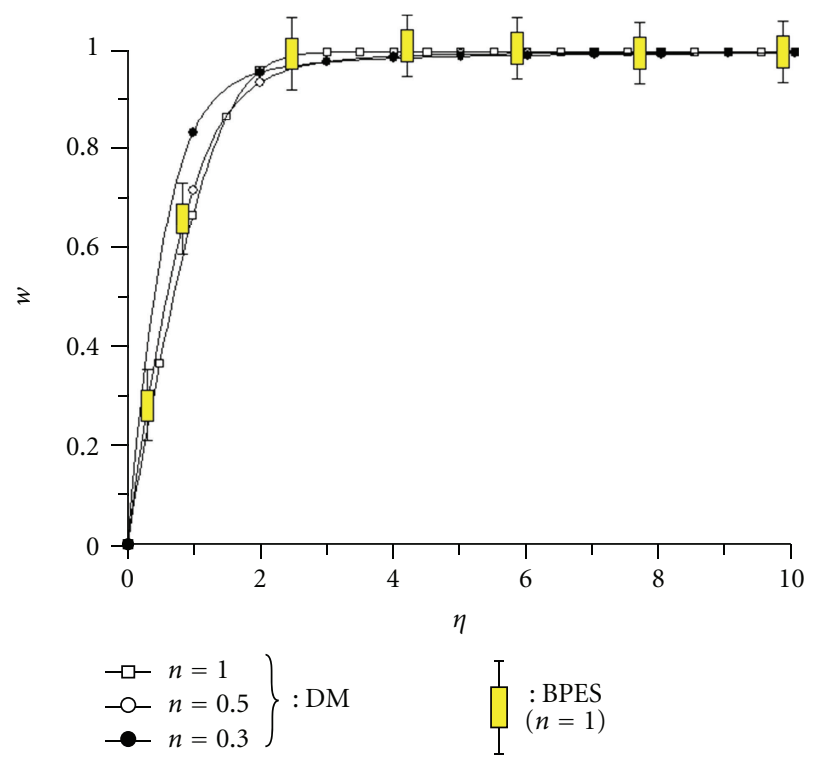

Figure 1: Dimensionless temperature for $Z^{*}=0.5, N_{Z \mathrm{~h}}=2.0$.

The final solution is derived by introducing the expression (29) in the system (15)-(18) and calculating the coefficients $\left.\xi_{j}^{\text {optim. }}\right|_{j=1 \ldots M}$ which minimize the functional determinant $\Delta$ :

$$
\begin{aligned}
\Delta=\mid & \left(\left|\sum_{j=1}^{M} \xi_{j}^{\text {optim. }} \times \Phi_{j}^{(2)}\right|\right)^{n-1}\left(\sum_{j=1}^{M} \xi_{j}^{\text {optim. }} \times \Phi_{j}^{(2)}\right) \\
& -\left(\sum_{j=1}^{M} \xi_{j}^{\text {optim. }} \times \Phi_{j}^{(0)}\right)\left(\sum_{j=1}^{M} \xi_{j}^{\text {optim. }} \times \Phi_{j}^{(1)}\right) \mid,
\end{aligned}
$$

where $\Phi_{j}^{(0)}, \Phi_{j}^{(1)}$, and $\Phi_{j}^{(2)}$ are calculated using the properties expressed by (32)-(34).

The solution is consequently:

$$
\begin{gathered}
w_{\text {sol. }}(\eta)=\frac{1}{2 M} \sum_{j=1}^{M} \xi_{j}^{\text {optim. }} \times B_{4 j}\left(\varpi_{j} \varepsilon(\eta)\right), \\
\varepsilon(\eta)=(\eta+1) e^{-\eta} .
\end{gathered}
$$

\section{Numerical Results}

The heat transfer of pseudoplastic power law fluids aligned with a semi-infinite plate is investigated in the presence of viscous dissipation. Numerical solutions are achieved using the discretization shooting method and the Boubaker polynomials expansion echeme (BPES). Figures 1-4 show the dimensionless temperature profiles for different power law index $n$, the Zheng number $N_{Z h}$ and $Z^{*}$. It is observed that the length scale of thermal diffusion is significantly different for the values of parameters. On the whole, the thermal diffusion ratio increases with the increase of $N_{Z h}$ and $Z^{*}$.

Figure 1 depicts the effect of power-law index $n$ on the temperature profiles using the two methods (Section 3, Section 4). It is a known fact that increasing values of $n$

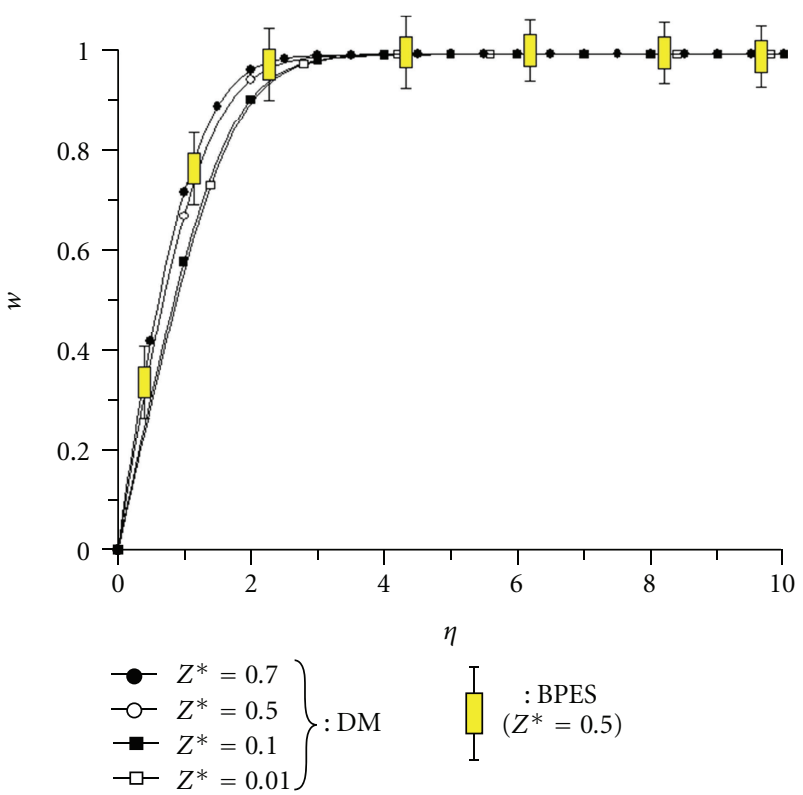

FIgURE 2: Dimensionless temperature for $n=0.8, N_{\mathrm{Zh}}=2.0$.

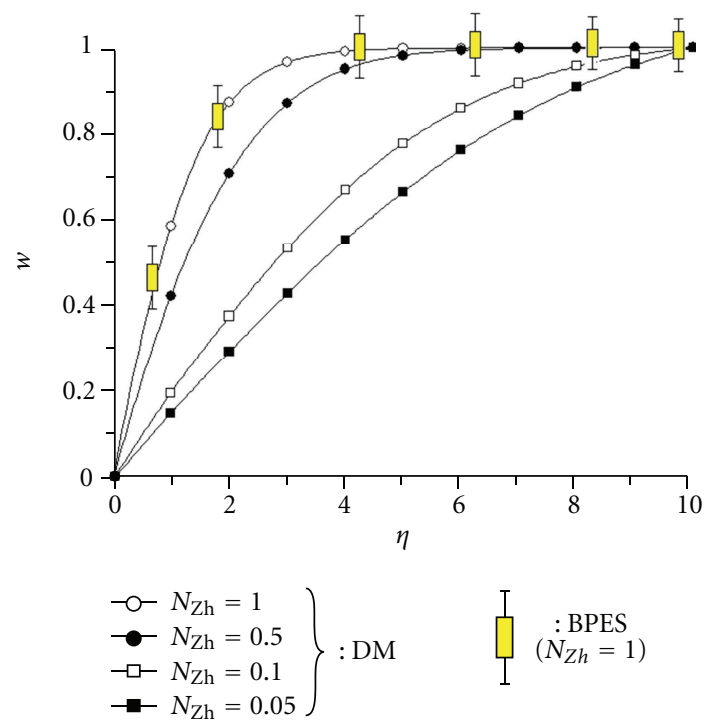

Figure 3: Dimensionless temperature for $n=0.8, Z^{*}=1.0$.

implies difference in temperature. The same is reiterated by Figure 1: the changing factor $n$ arises some perturbation in temperature profiles and lead to the varying $w$ for each $\eta$.

Figure 2 reveals the effect made by the viscous dissipation on the temperature. These profiles are well behaved and very little change occurs in the shapes of profiles with the varying parameter $Z^{*}$. The different values of $Z^{*}$ contribute little to the thickness of the thermal boundary layer.

Figures 3-4 show temperature profiles for fixed $Z^{*}$ and $n$ with different values of $N_{Z h}$. For each $N_{Z h}\left(N_{Z h}>0\right)$, the thermal diffusion ratio increases with the increasing in $N_{Z h}$ as recorded earlier by Zheng et al. [38] and Ece and Buyuk [19]. It is evident that small values of $N_{Z \mathrm{Zh}}$ result in thinning 


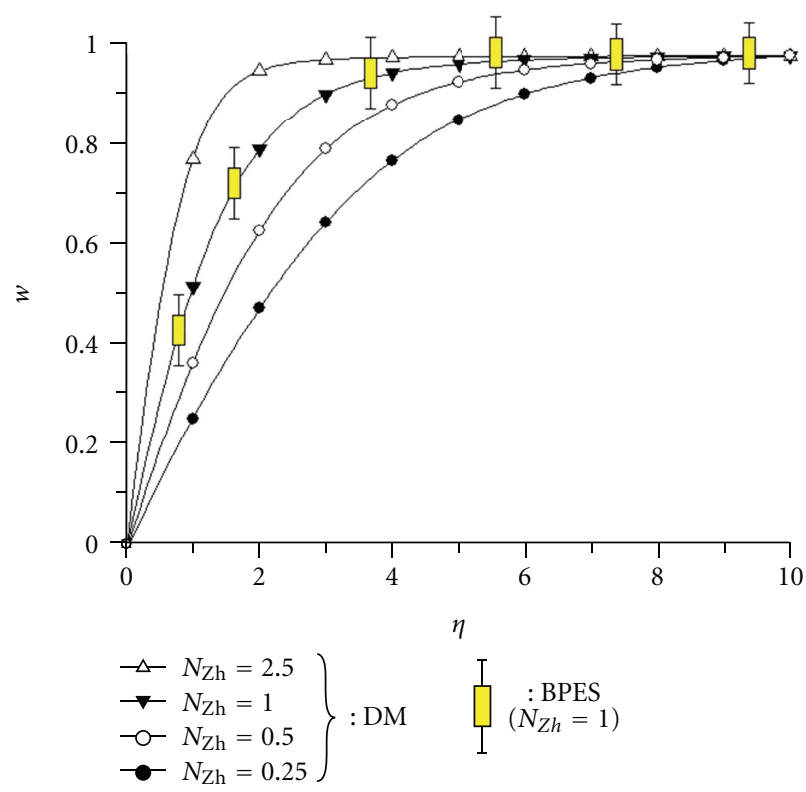

FIgURE 4: Dimensionless temperature for $=0.5, \quad Z^{*}=0.5$.

of the thermal boundary layer. This is similar to the effects of Prandtl number Pron heat transfer.

\section{Conclusions}

An investigation on heat transfer of pseudoplastic nonNewtonian fluids aligned with a semi-infinite plate is made. The boundary layer equations for both momentum and energy boundary layers have been developed. Numerical solutions are presented and the associated transfer behavior for different power-law index, and the Zheng number $N_{\mathrm{Zh}}$ and $Z^{*}$ are discussed. Two significant physical phenomena are observed, that is, large values of $N_{\mathrm{Zh}}$ result in thicker thermal boundary layers, and, the different values of $Z^{*}$ contribute little to the thickness of the thermal boundary layer.

\section{Nomenclature}

$c_{P}$ : $\quad$ Fluid specific heat $\left(\mathrm{J} \mathrm{kg}^{-1} \mathrm{C}^{-1}\right)$

$f: \quad$ Stream function (dimensionless)

$K$ : $\quad$ Consistency index

$k$ : $\quad$ Thermal conductivity $\left(\mathrm{W} \mathrm{kg}^{-1} \mathrm{~K}^{-1}\right.$ )

$N_{\mathrm{Zh}}$ : Zheng number (dimensionless)

$n$ : $\quad$ Power-law index (dimensionless)

$T: \quad$ Temperature (K)

$U, V$ : Velocity components along $X$ and $Y$ directions $\left(\mathrm{m} \mathrm{s}^{-1}\right)$

$X, Y$ : Cartesian coordinates along the plate and normal to it $(\mathrm{m})$.
Greek symbols

$\alpha$ : Fluid thermal diffusivity $\left(\mathrm{m}^{2} \mathrm{~s}^{-1}\right)$

$\eta$ : Similarity variable (dimensionless)

$\theta$ : Normalized temperature (dimensionless)

$\varpi$ : Temperature function (dimensionless)

$\psi$ : Stream function (dimensionless)

$v$ : Kinematic viscosity $\left(\mathrm{m} \mathrm{s}^{-1}\right)$

$\rho$ : Density $\left(\mathrm{Kg} \mathrm{m}^{-3}\right)$

$\omega$ : Constant (dimensionless).

Subscripts

$w, \infty$ : Conditions at the surface and in the free stream, respectively.

\section{Acknowledgment}

The work is supported by the National Natural Science Foundations of China (No. 50936003), the Open Project of State Key Lab. for Adv. Metals and Materials (2009Z-02), and Research Foundation of Engineering Research Institute of USTB.

\section{References}

[1] W. R. Schowalter, "The application of boundary-layer theory to power-law pseudo plastic fluids: similar solutions," AIChE Journal, vol. 6, pp. 24-28, 1960.

[2] A. Acrivos, M. J. Shah, and E. E. Petersen, "Momentum and heat transfer in laminar Boundary-Layer flows of nonNewtonian fluids past external surfaces," AIChE Journal, vol. 6, pp. 312-317, 1960.

[3] T. Y. Wang, "Mixed convection from a vertical plate to nonNewtonian fluids with uniform surface heat flux," International Communications in Heat and Mass Transfer, vol. 22, no. 3, pp. 369-380, 1995.

[4] T. Y. Wang, "Mixed convection heat transfer from a vertical plate to non-Newtonian fluids," International Journal of Heat and Fluid Flow, vol. 16, no. 1, pp. 56-61, 1995.

[5] F. M. Hady, "Mixed convection Boundary-Layer flow of nonNewtonian fluids on a horizontal plate," Applied Mathematics and Computation, vol. 68, no. 2-3, pp. 105-112, 1995.

[6] K. Kumari, I. Pop, and H. S. Takhar, "Free convection in power-law fluids near a three-dimensional stagnation point," International Journal of Heat and Fluid Flow, vol. 18, pp. 625631, 1997.

[7] T. G. Howell, D. R. Jeng, and K. J. De Witt, "Momentum and heat transfer on a continuous moving surface in a power law fluid," International Journal of Heat and Mass Transfer, vol. 40, no. 8, pp. 1853-1861, 1997.

[8] J. H. Rao, D. R. Jeng, and K. J. De Witt, "Momentum and heat transfer in a power-law fluid with arbitrary injection/suction at a moving wall," International Journal of Heat and Mass Transfer, vol. 42, no. 15, pp. 2837-3847, 1999.

[9] I. A. Hassanien, A. A. Abdullah, and R. S. R. Gorla, "Flow and heat transfer in a power-law fluid over a nonisothermal stretching sheet," Mathematical and Computer Modelling, vol. 28, no. 9, pp. 105-116, 1998. 
[10] N. Luna, F. Méndez, and C. Treviño, "Conjugated heat transfer in circular ducts with a power-law laminar convection fluid flow," International Journal of Heat and Mass Transfer, vol. 45, no. 3, pp. 655-666, 2002.

[11] A. Pinarbasi and M. Imal, "Viscous heating effects on the linear stability of Poiseuille flow of an inelastic fluid," Journal of Non-Newtonian Fluid Mechanics, vol. 127, no. 2-3, pp. 6771, 2005.

[12] C.-H. Chen, "Effect of viscous dissipation on heat transfer in a non-Newtonian liquid film over an unsteady stretching sheet," Journal of Non-Newtonian Fluid Mechanics, vol. 135, no. 2-3, pp. 128-135, 2005.

[13] H. I. Andersson, K. H. Bech, and B. S. Dandapat, "Magnetohydrodynamic flow of a power-law fluid over a stretching sheet," International Journal of Non-Linear Mechanics, vol. 27, no. 6, pp. 929-936, 1992.

[14] R. Cortell, "A note on magnetohydrodynamic flow of a powerlaw fluid over a stretching sheet," Applied Mathematics and Computation, vol. 168, no. 1, pp. 557-566, 2005.

[15] M. A. A. Mahmoud and M. A. E. Mahmoud, "Analytical solutions of hydromagnetic Boundary-Layer flow of a nonNewtonian power-law fluid past a continuously moving surface," Acta Mechanica, vol. 181, no. 1-2, pp. 83-89, 2006.

[16] I. Pop, M. Rashidi, and R. S. R. Gorla, "Mixed convection to power-law type non-Newtonian fluids from a vertical wall," Polymer-Plastics Technology and Engineering, vol. 30, no. 1, pp. 47-66, 1991.

[17] I. Pop, "Boundary layer flow at a three-dimensional stagnation point in power-law non-Newtonian fluids," International Journal of Heat and Fluid Flow, vol. 14, no. 4, pp. 408-412, 1993.

[18] R. S. R. Gorla, I. Pop, and J. K. Lee, "Convective wall plume in power-law fluid: second-order correction for the adiabatic wall," Warme-und Stoffubertragung, vol. 27, no. 8, pp. 473-479, 1992.

[19] M. C. Ece and E. Buyuk, "Similarity solutions for free convection to power-law fluids from a heated vertical plate," Applied Mathematics Letters, vol. 33, no. 1, pp. 119-125, 1990.

[20] L. Zheng, X. Zhang, and C. Lu, "Heat transfer for power law non-Newtonian fluids," Chinese Physics Letters, vol. 23, no. 12, pp. 3301-3304, 2006.

[21] L. Zheng, X. Zhang, and L. Ma, "Fully developed convective heat transfer of power law fluids in a circular tube," Chinese Physics Letters, vol. 25, no. 1, pp. 195-197, 2008.

[22] A. Belhadj, O. Onyango, and N. Rozibaeva, "Boubaker polynomials expansion scheme-related heat transfer investigation inside keyhole model," Journal of Thermophysics and Heat Transfer, vol. 23, no. 3, pp. 639-640, 2009.

[23] A. S. Kumar, "An analytical solution to applied mathematicsrelated Love's equation using the Boubaker polynomials expansion scheme," Journal of the Franklin Institute, vol. 347, no. 9, pp. 1755-1761, 2010.

[24] A. Belhadj, J. Bessrour, M. Bouhafs, and L. Barrallier, "Experimental and theoretical cooling velocity profile inside laser welded metals using keyhole approximation and Boubaker polynomials expansion," Journal of Thermal Analysis and Calorimetry, vol. 97, no. 3, pp. 911-920, 2009.

[25] P. Barry and A. Hennessy, "Meixner-type results for Riordan arrays and associated integer sequences, section 6: the Boubaker polynomials," Journal of Integer Sequences, vol. 13, pp. 1-34, 2010.

[26] M. Agida and A. S. Kumar, "A Boubaker polynomials expansion scheme solution to random Love's equation in the case of a rational Kernel," Electronic Journal of Theoretical Physics, vol. 7, no. 24, pp. 319-326, 2010.

[27] A. Yildirim, S. T. Mohyud-Din, and D. H. Zhang, "Analytical solutions to the pulsed Klein-Gordon equation using modified variational iteration method (MVIM) and Boubaker polynomials expansion scheme (BPES)," Computers and Mathematics with Applications, vol. 59, no. 8, pp. 2473-2477, 2010.

[28] J. Ghanouchi, H. Labiadh, and K. Boubaker, "An attempt to solve the heat transfer equation in a model of pyrolysis spray using 4q-order m-Boubaker polynomials," International Journal of Heat and Technology, vol. 26, no. 1, pp. 49-53, 2008.

[29] O. B. Awojoyogbe and K. Boubaker, "A solution to Bloch NMR flow equations for the analysis of hemodynamic functions of blood flow system using m-Boubaker polynomials," Current Applied Physics, vol. 9, no. 1, pp. 278-288, 2009.

[30] S. Slama, J. Bessrour, and K. B. Ben Mahmoud, "Study of temperature $3 \mathrm{D}$ profile during weld heating phase using Boubaker polynomials expansion," Thermochimica Acta, vol. 55, pp. 401-404, 2009.

[31] S. Slama, M. Bouhafs, and K. B. Ben Mahmoud, "A Boubaker polynomials solution to heat equation for monitoring A3 point evolution during resistance spot welding," International Journal of Heat and Technology, vol. 26, no. 2, pp. 141-146, 2008.

[32] S. Tabatabaei, T. Zhao, O. Awojoyogbe, and F. Moses, "Cutoff cooling velocity profiling inside a keyhole model using the Boubaker polynomials expansion scheme," Heat and Mass Transfer/Waerme- und Stoffuebertragung, vol. 45, no. 10, pp. 1247-1251, 2009.

[33] S. Fridjine and M. Amlouk, "A new parameter: an ABACUS for optimizing PVT hybrid solar device functional materials using the Boubaker polynomials expansion scheme," Modern Physics Letters B, vol. 23, no. 17, pp. 2179-2182, 2009.

[34] H. Rahmanov, "A solution to the non linear korteweg-de-vries equation in the particular case dispersion-adsorption problem in porous media using the spectral Boubaker polynomials expansion scheme (BPES)," Studies in Nonlinear Sciences, vol. 2, no. 1, pp. 46-49, 2011.

[35] A. Milgram, "The stability of the Boubaker polynomials expansion scheme (BPES)-based solution to Lotka-Volterra problem," Journal of Theoretical Biology, vol. 271, no. 1, pp. 157-158, 2010.

[36] M. Benhaliliba, C. E. Benouis, K. Boubaker et al., "A new guide to thermally optimized doped oxides monolayer spray-grown solar cells: the amlouk-Boubaker optothermal expansivity qab," in Solar Cells, L. A. Kosyachenko, Ed., pp. 27-41, InTech, 2011.

[37] M. Dada, M. A. Aweda, O. B. Awojoyogbe, and K. Boubaker, "A polynomial expression to the magnetic phase-shift induced in leon-vigmond model of the human heart," Physical Journal of Mechanics in Medicine an Biology, vol. 12, no. 1, pp. 1-7, 2012.

[38] L. C. Zheng, X. X. Zhang, K. Boubaker, U. Yücel, E. GargouriEllouze, and A. Yıldırım, "Similarity and Boubaker polynomials expansion scheme BPES comparative solutions to the heat transfer equation for incompressible non-newtonian fluids: case of laminar boundary energy equation," The European Physical Journal, vol. 55, no. 21102, 5 pages, 2011. 

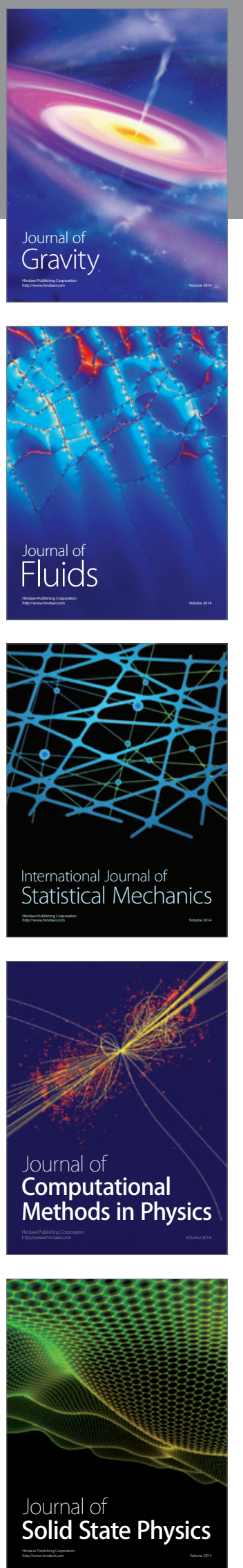
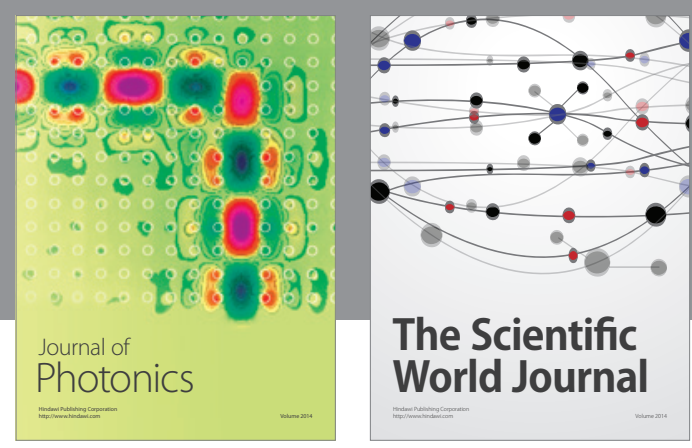

The Scientific World Journal

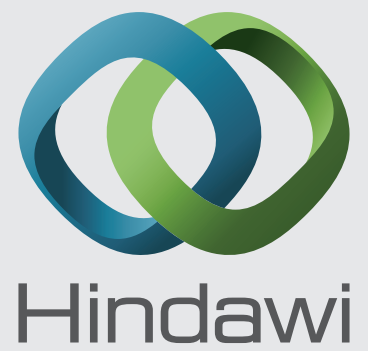

Submit your manuscripts at http://www.hindawi.com
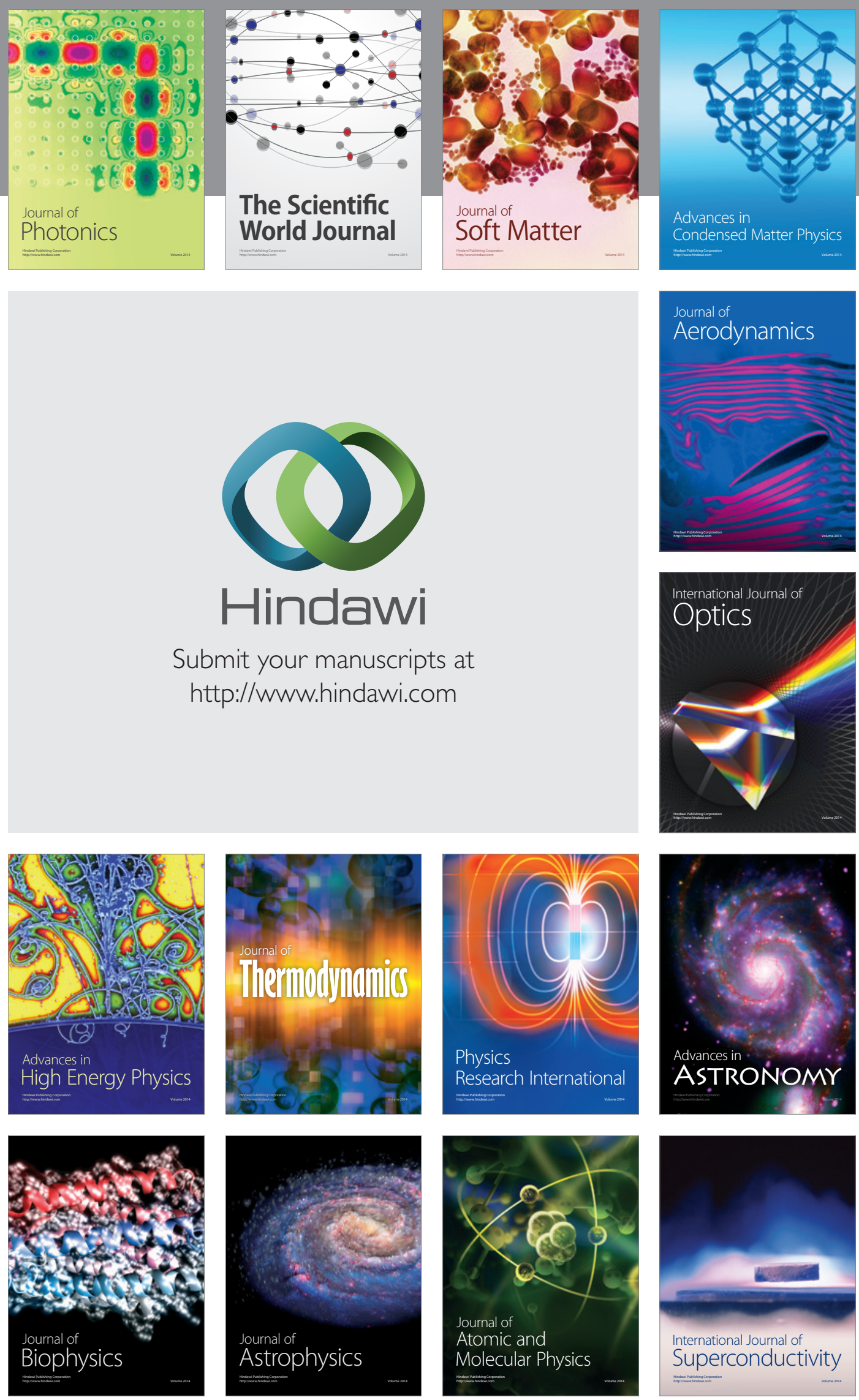
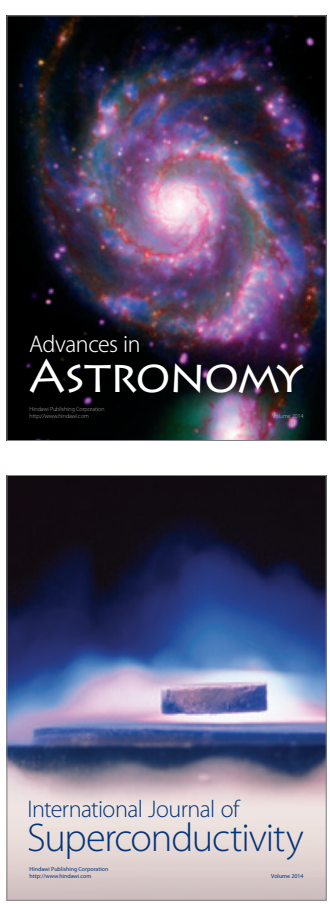